\title{
Clinical effectiveness of labia minora reduction surgery
}

\author{
Jeong-Ho Seo, MD, PhD, Jun-Woo Jo, PhD, Yoon-Ho Jo, MD, PhD \\ Department of Obstetrics and Gynecology, Yoonho Hospital, Seoul, Rep. of Korea
}

Background: The demand for labia minora reduction operation has been increasing nowadays but there have been some questions about the safety and effectiveness of labioplasty surgery.

Objective: The purpose of this study was to evaluate the effectiveness and satisfaction among patients who have undergone labia minora reduction surgery.

Methods: Patients who had undergone labia minora reduction from January 2015 to December 2015 were reviewed. The procedure applied in this study was edge excision technique.

Results: Eighty-four patients underwent labia minora reduction surgery. Of these, 41 patients $(48.8 \%)$ underwent labia minora reduction surgery in combination with other procedures. All of the patients were satisfied with the outcome of the edge resection surgery. The main operative indications were regarding labial appearance and functional discomfort. Of these, one patient (1.2\%) experienced the complication of postoperative bleeding, which was recovered without any additional treatment. There were no serious complications requiring reoperation.

Conclusion: Labiaplasty using an edge excision technique is an effective and safe operation, has a low complication rate, and makes patients satisfied with the outcome of the labiaplasty.

Keywords: labia minora reduction; edge excision technique; labiaplasty

\section{Introduction}

Nowadays, many women pay attention to the appearance of the labia minora because of increasing discussion on social media. Exposure to plastic surgery reality television also contributes to easier decision-making regarding labiaplasty [1]. Removal of pubic hair may cause the labia minora to appear more outstanding.

The etiology about hypertrophy of the labia minora is not well-known. Most labia minora hypertrophy can be congenital, but some instances can be acquired, including due to chronic irritation, androgen influences, age-related changes, childbirth and the effects of gravity [2].
The patients who seek labiaplasty usually have one or two problems. First, aesthetic discomfort causes decreased selfesteem, anxiety and embarrassment due to dissatisfaction with the labia minora appearance. Second, functional discomforts related to hypertrophied labia minora include pain while wearing tight clothing, or during sexual and athletic activities. Sometimes, functional problems are related to hygiene or infection $[3,4]$.

The American College of Obstetricians and Gynecologists (ACOG) has raised several questions about the safety and effectiveness of female genital surgery. Because of the lack of clinical data, the ACOG has suggested that all female genital surgery including labia minora reduction may have postoperative com-

Received July 6 2016, Revised March 2 2017, Accepted March 32017

Corresponding author: Jeong-Ho Seo, Department of Obstetrics and Gynecology, Yoonho Hospital, 304 Apgujeong-ro, Gangnam-gu, Seoul 06017, Rep. of Korea

Tel: 82-2-512-0500, Fax: 82-2-512-0537, E-mail: drseokr@hanmail.net

This is an Open Access article distributed under the terms of the Creative Commons Attribution Non-Commercial License (http://creativecommons.org/licenses/by-nc/4.0), which permits unrestricted non-commercial use, distribution, and reproduction in any medium, provided the original work is properly cited.

Copyright (@) 2017. Korean Society of Korean Cosmetic Surgery and medicine (KSKCS \& KCCS). 
plications. For example, the altered sensation of the genitalia, dyspareunia, scarring and decreased sexual satisfaction may occur following female genital surgery $[5,6]$.

Although, the effectiveness and safety following labiaplasty have been controversial [7], the high rate of patient satisfaction makes women undergo labiaplasty. The purpose of this study is to evaluate the effectiveness of labia minora reduction surgery, including associated complications.

\section{Materials and methods}

Labia minora reduction surgery was performed for 84 patients from January 2015 to December 2015. All of the proce- dures were performed in the outpatient clinic under intravenous anesthesia using propofol with patients in the lithotomy position.

A local anesthetic that consisted of $2 \%$ lidocaine was infiltrated between the two skin layers of the labium minora. The resected labia minora is marked. The marked redundant skin was excised with scissors (Fig. 1).

After the edge excision technique was used, careful hemostasis using electrocautery was needed prior to closure. At least a labial width of $1 \mathrm{~cm}$ should be left to prevent complications including scarring, dyspareunia, sensory loss and chronic pain. The excised skin area is stitched using 4-0 or 5-0 vicryl ${ }^{\mathbb{B}}$ (Ethicon, Somerville, NJ, USA). A sequential photographs of the surgical
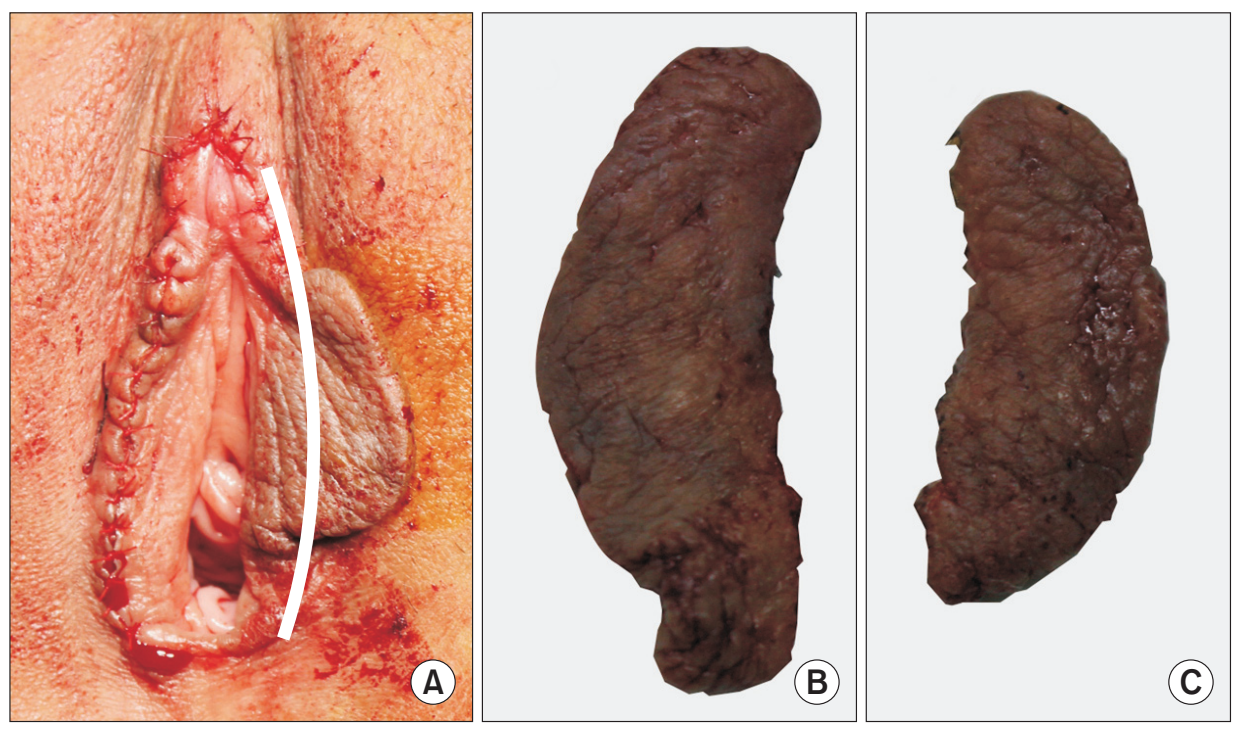

Fig. 1. Operative figures. (A) Closure of right side labium minor and preoperative marking for left labium minor reduction. (B) Appearance after excision of the rightside labium minor. (C) Appearance after excision of the left-side labium minor.
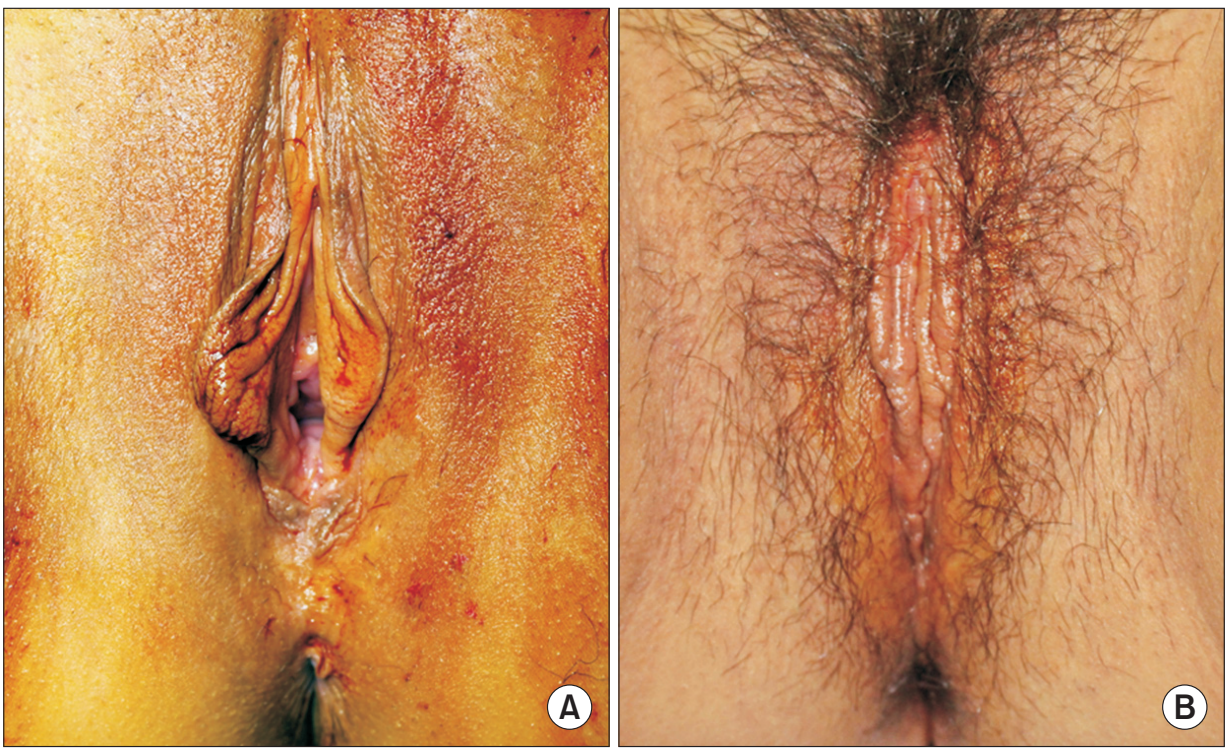

Fig. 2. Photographs of a 35-year-old female who underwent bilateral labia minora reduction. Preoperative view (A) and postoperative view at two months (B). 

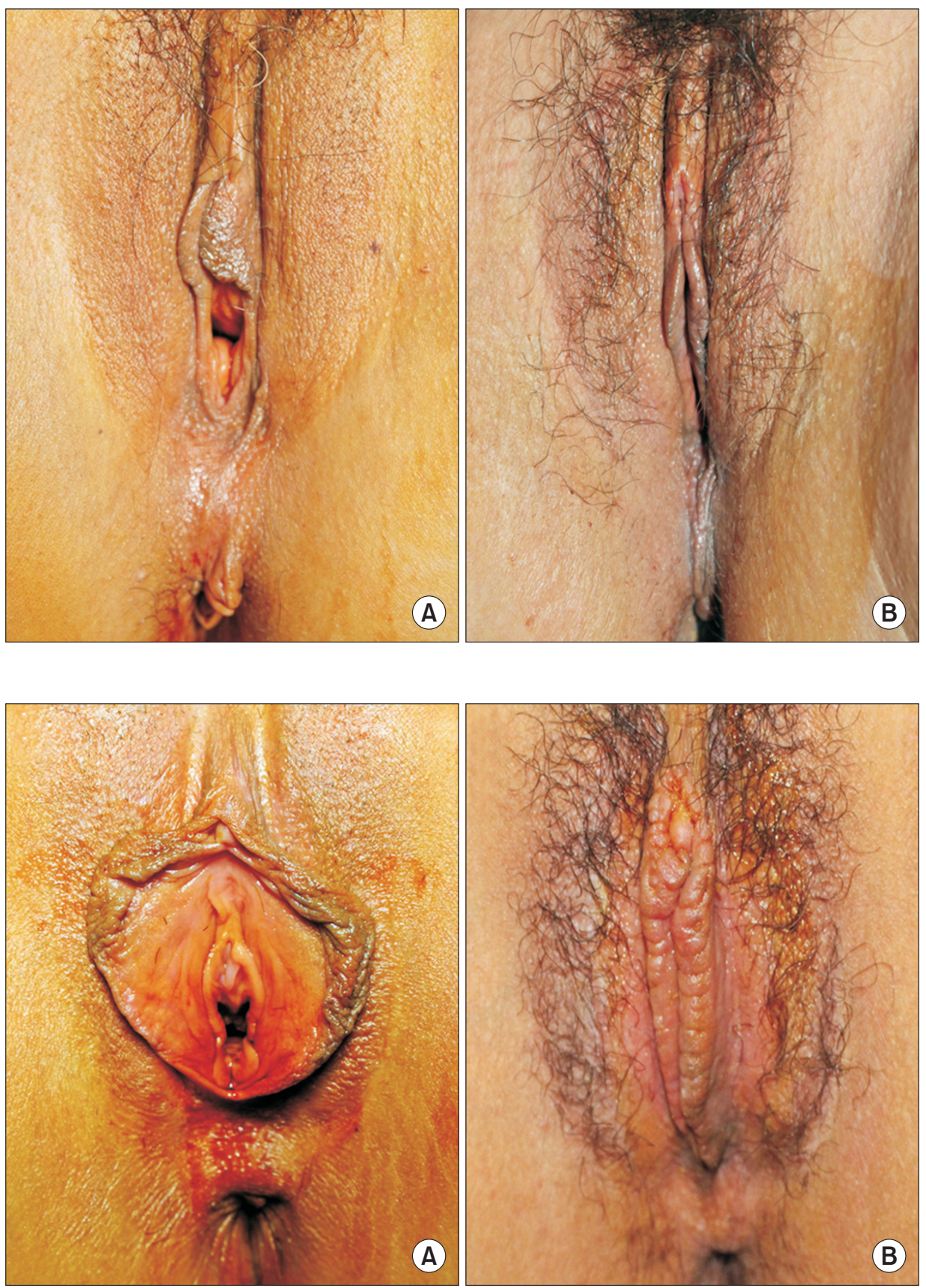

Fig. 3. Photographs of a 40-year-old female undergoing bilateral labia minora reduction. Preoperative view of labia minora (A) and postoperative view at one month (B). technique is shown in Fig. 2-4.

All of the patients were discharged on the day of surgery. Sexual intercourse was not allowed for two months postoperatively. The patients were requested to return for follow-up at one week, one month, two months and six months thereafter.

\section{Results}

Eighty-four patients undergoing labia minora reduction surgery using the edge excision technique were discharged on the day of the operation from our hospital. Of these 84 patients, 35 (41.7\%) had functional problems, including discomfort during sexual intercourse or when wearing tight clothing, while 78 women $(92.9 \%)$ had aesthetic issues including anxiety, lowered self-esteem and embarrassment due to hypertrophy of the labia minora. Of these, 41 patients (48.8\%) underwent labia minora reduction in combination with another procedure (Table 1).

The mean age of the patients was 36.0 years (range 20-53), and the median duration of the operation was 95.4 minutes (range 30-125), including those that were combined proce- 
Table 1. Overview of the combined procedures involving reduction of the labia minora

\begin{tabular}{lc}
\hline \multicolumn{1}{c}{ Procedures } & Number of patients \\
\hline Vaginal tightening & $36(42.9 \%)$ \\
Reduction of labia majora & $2(2.4 \%)$ \\
Sling operation for stress urinary incontinence & $3(3.6 \%)$ \\
\hline
\end{tabular}

Table 2. Patient characteristics and operative results

\begin{tabular}{lc}
\hline \multicolumn{1}{c}{ Characteristics } & Number of patients $(\mathbf{n}=\mathbf{8 4})$ \\
\hline Age (years) & 36 (range 20-53 ) \\
\hline Operative time (minutes) & $95.4($ range $30-125)$ \\
\hline Indications of operation & $35(41.7 \%)$ \\
\hline Functional issues & $78(92.9 \%)$ \\
Aesthetic issues & $84(100 \%)$ \\
\hline Overall patient satisfaction & $1(1.2 \%)$ \\
\hline Postoperative complications & \\
\hline
\end{tabular}

dures. All of the patients were followed up with postoperatively, and all reported being satisfied with the outcome of the edge resection surgery. None of the patients complained of functional or aesthetic problems following the procedure. There were no complaints of issues with sexual dysfunction following operation. One patient (1.2\%) experienced postoperative bleeding, which was managed without any treatment, and no major complications occurred. All of the patients who had experienced functional or aesthetic discomfort reported the disappearance of discomfort due to hypertrophy of the labia minora (Table 2).

\section{Discussion}

The demand for labia minora reduction surgery has significantly increased in many countries. In England, the number of labia minora reduction operations in the National Health Service has increased fivefold in the past decade [8]. Lately, the most common techniques have been labiaplasty and vaginal tightening procedures [9].

It is thought that hypertrophy of the labia minora is a variant of the normal anatomy [10]. There is no absolute definition for hypertophy of the labia minora. Friedrich suggested that the normal distance from the base to the edge of the labia minora under lateral mild traction might be less than $5 \mathrm{~cm}$ [11]. However, most of the patients seeking labiaplasty in our study have less than $5 \mathrm{~cm}$ width labia minora.

The main indications of operation in this study are aesthetic problems (92.9\%). Many other studies indicate that $85.7 \%$ to $100 \%$ of patients have aesthetic issues [12-15]. Therefore, aesthetic discomfort is the main indication for correction, includ-
Table 3. Preoperative indications for labiaplasty

\begin{tabular}{lcc}
\hline \multicolumn{1}{c}{ Study } & $\begin{array}{c}\text { Total number of } \\
\text { patients }\end{array}$ & $\begin{array}{c}\text { Aesthetic } \\
\text { problems }\end{array}$ \\
\hline Present study & 84 & $72(92.9 \%)$ \\
\hline Rouzier 2000 [12] & 163 & $142(87 \%)$ \\
\hline Gilardo 2004 [13] & 15 & $15(100 \%)$ \\
\hline Munhoz 2006 [14] & 21 & $21(100 \%)$ \\
\hline Heusse 2009 [15] & 14 & $12(85.7 \%)$ \\
\hline
\end{tabular}

Table 4. Postoperative patient satisfaction

\begin{tabular}{cc}
\hline Study & $\begin{array}{c}\text { Satisfaction result } \\
\text { (evaluated by patient) }\end{array}$ \\
\hline Present study & $84 / 84(100 \%)$ \\
Goodman 2010 & $236 / 258(91.6 \%)$ \\
\hline Rouzier 2000 & $81 / 98(83 \%)$ \\
Gilardo 2004 & $15 / 15(100 \%)$ \\
Munhoz 2006 & $20 / 21(95 \%)$ \\
\hline Heusse 2009 & $10 / 12(83 \%)$ \\
\hline
\end{tabular}

ing in our study (Table 3). Like other aesthetic surgeries, more labiaplasties has been performed for aesthetic problems than functional problems.

There are three main kinds of labiaplasty techniques, including the edge excision technique, wedge resection technique and de-epithelialization technique $[16,17]$. Each has its own advantages and drawbacks. Ellsworth et al.[18] reported that the three different labia minora reduction techniques were useful and effective, though he specifically recommended the edge excision technique for large labia minora patients.

We performed 84 labiaplasty procedures using the edge excision technique. Edge excision of the labia minora is a technically simple and safe procedure. However, it should be remembered that a minimal labia minora width is $1 \mathrm{~cm}$ after edge excision surgery for preventing scarring, dyspareunia, sensual loss and/or chronic pain following the procedure [19].

In our study, one patient experienced postoperative bleeding. In other studies, complications reportedly occurred in 134 (6.76\%) of the total 1,981 patients. The most common complications were wound dehiscence, hematoma and postoperative bleeding. No serious complications occurred. Revision surgery was needed in 82 patients ( $4.1 \%$ ) due to wound healing complications or postoperative bleeding [20]. All of the studies, including our study, had very low complication rates. It is believed that the aesthetic reduction of the labia minora procedure is safe.

Goodman et al.[21] published the results of their large multicenter study conducted with 258 patients who had surgery. Of these, 236 patients $(91.6 \%)$ were satisfied with the outcome. In 
our study, all of the patients were satisfied with the outcome of the edge resection surgery. Most studies have reported that patient satisfaction is close to $90 \%$ or more (Table 4 ).

\section{Conclusion}

In conclusion, hypertrophy of the labia minora leads to functional and aesthetic problems. Labioplasty using an edge excision technique is a safe and effective method that is associated with high satisfaction and a low complication rate. Therefore, we would better recommend labiaplasty for women who have functional and aesthetic problems due to hypertrophy of the labia minora.

\section{Conflicts of interest}

The authors have nothing to disclose.

\section{References}

1. Crockett RJ, Pruzinsky T, Persing JA. The influence of plastic surgery "reality TV" on cosmetic surgery patient expectations and decision making. Plast Reconstr Surg 2007;120:316-24.

2. Kruk-Jeromin J, Zieliński T. [Hypertrophy of labia minorapathomorphology and surgical treatment]. Ginekol Pol 2010; 81:298-302. Polish.

3. Miklos JR, Moore RD. Labiaplasty of the labia minora: patients' indications for pursuing surgery. J Sex Med 2008;5: 1492-5.

4. Zwier S. "What motivates her": motivations for considering labial reduction surgery as recounted on women's online communities and surgeons' websites. Sex Med 2014;2:16-23.

5. Committee on Gynecologic Practice, American College of Obstetricians and Gynecologists. ACOG committee opinion no. 378: vaginal "rejuvenation" and cosmetic vaginal procedures. Obstet Gynecol 2007;110:737-8.

6. Shaw D, Lefebvre G, Bouchard C, Shapiro J, Blake J, Allen L, et al. Female genital cosmetic surgery. J Obstet Gynaecol Can 2013;35:1108-14.

7. Pauls RN. We are the correct physicians to treat women re- questing labiaplasty. Am J Obstet Gynecol 2014;211:218.el.

8. National Health Service. Hospital episode statistics [Internet]. Leeds: NHS Digital; 2017. Available from: http://www.hesonline.nhs.uk.

9. Dobbeleir JM, Landuyt KV, Monstrey SJ. Aesthetic surgery of the female genitalia. Semin Plast Surg 2011;25:130-41.

10. Radman HM. Hypertrophy of the labia minora. Obstet Gynecol 1976;48(1 Suppl):78S-9S.

11. Friedrich EG. Vulvar disease. 2nd ed. Philadelphia: Saunders; 1983.

12. Rouzier R, Louis-Sylvestre C, Paniel BJ, Haddad B. Hypertrophy of labia minora: experience with 163 reductions. Am J Obstet Gynecol 2000;182:35-40.

13. Giraldo F, González C, de Haro F. Central wedge nymphectomy with a 90-degree Z-plasty for aesthetic reduction of the labia minora. Plast Reconstr Surg 2004;113:1820-5.

14. Munhoz AM, Filassi JR, Ricci MD, Aldrighi C, Correia LD, Aldrighi JM, et al. Aesthetic labia minora reduction with inferior wedge resection and superior pedicle flap reconstruction. Plast Reconstr Surg 2006;118:1237-47.

15. Heusse JL, Cousin-Verhoest S, Aillet S, Watier E. [Refinements in the labia minor reduction procedures]. Ann Chir Plast Esthet 2009;54:126-34. French.

16. Alter GJ. Central wedge nymphectomy with a 90-degree Zplasty for aesthetic reduction of the labia minora. Plast Reconstr Surg 2005;115:2144-5; author reply 2145.

17. Choi HY, Kim KT. A new method for aesthetic reduction of labia minora (the deepithelialized reduction of labioplasty). Plast Reconstr Surg 2000;105:419-22.

18. Ellsworth WA, Rizvi M, Lypka M, Gaon M, Smith B, Cohen B, et al. Techniques for labia minora reduction: an algorithmic approach. Aesthetic Plast Surg 2010;34:105-10.

19. Scholten E. Female genital cosmetic surgery--the future. J Plast Reconstr Aesthet Surg 2009;62:290-1.

20. Oranges CM, Sisti A, Sisti G. Labia minora reduction techniques: a comprehensive literature review. Aesthet Surg J 2015;35:419-31.

21. Goodman MP, Placik OJ, Benson RH 3rd, Miklos JR, Moore $\mathrm{RD}$, Jason RA, et al. A large multicenter outcome study of female genital plastic surgery. J Sex Med 2010;7:1565-77. 